\title{
Sustainability and Participation in the Digital Commons
}

\author{
David Franquesa and Leandro Navarro, Universitat Politècnica de Catalunya ${ }^{1}$
}

As farmers depend on irrigation, pastures and water, digital societies depend on networking infrastructures, such as the Internet and digital devices that produce and support connectivity and interaction. We argue, that what applies to critical natural resource systems (e.g. an irrigation system or fishing grounds), also applies to digital resources. This includes not only designing sustainable systems and interfaces for the digital world, but systems that require social and environmental awareness, while taking responsibility, and recognizing the gaps, limits and impacts of global-scale digital artifacts.

Economists have studied how communities manage critical resources including irrigation systems, fishing grounds, pastures, forests, and water. As an alternative to purely private or purely public services and infrastructures, Elinor Ostrom, 2009 Nobel Prize winner in Economics, suggested the commons as a collective management alternative [5]. Common property systems include social arrangements that regulate the preservation, maintenance, and consumption of natural or human-made resource systems, also called common-pool resources (CPR). These CPR consist of a core resource (e.g. irrigation system, forest, grassland) that provides a limited quantity of extractable fringe units that can be harvested or consumed (e.g. water, wood, grass). The size or characteristics of CPR goods make it costly to exclude potential beneficiaries from its use. However, CPR also face problems of congestion and overuse, the "tragedy of the commons".

Yet, according to the Internet Society ${ }^{2}$, the majority of the world's population does not have adequate Internet access. This implies that the Internet cannot provide adequate service to the general public nor is it able to reach everyone fairly.

Despite the lack or unequal access to digital devices and connectivity, somewhat ironically, digital devices are already an environmental problem. There are more digital devices on planet earth (e.g., desktops, laptops, tablets, and smart phones) than people. Electronic waste (e-waste) is the largest waste stream, most of it discarded in general waste leading to a loss of secondary resources [3]. Therefore, like many other human activities, the productions of digital devices and infrastructure are challenging the limits of sustainability within our natural environment.

It is well established that there is an access gap between citizens who can afford a digital device and an Internet connection and those who cannot. Citizens unable to access digital tools are too often confined to the lower or peripheral edge of the society for economic or geographic reasons, such as living in a underserved areas, without access to digital interaction. As a result of this inaccessibility, such groups are denied full involvement in mainstream economic, political, cultural and social activities, which may also mean disadvantages or exclusion from critical services such as health, education, knowledge, and therefore development [4].

1 Published with DOI: /10.1145/3058139 in ACM Interactions Magazine, May-June 2017

2 http://www.internetsociety.org/globalinternetreport/ 
If access to digital devices and access to connectivity (the Internet) has a critical impact on both social inclusion and on our natural environment, we argue for positioning the infrastructure for digital social interaction as a resource commons, and therefore that citizens should decide collectively about the limits, congestion, management and preservation of that infrastructure. This line of argumentation leads us to consider the governance of these resource systems as common property. Governance issues lead to considerations of human rights, and the right of everyone to participate in the governance of the digital world, instead of just the private elite who design and control the fabric of public digital space.

Are we all citizens of the digital world in equal terms (a democracy)? Or instead, are there first-class citizens (with the right to make design and development decisions) and second-class citizens (just users or consumers)? What do you think? There are multiple sides in this: researchers try to understand how we interact, designers develop interfaces, device manufacturers build and sell digital devices, telecom and Internet service providers offer connectivity, content providers offer services, and citizens consume these digital devices, connections and services throughout their daily lives. Is this a democracy or a farm where the feed is "free" Internet services and the crop is consumer data?

\section{Social interactions and access rights}

A commons is governed, according to rules adhering to the commons frameworks, by a community. This community may be composed by several types of actors with roles, rights, obligations and potential conflicts of interest. The bundle of rights [7] becomes a useful analytical grid to analyze social interactions. The bundle of rights includes rules related to:

- Access: to enter and use, where authorized users (customers, buyers, subscribers) are given access to a device or a network,

- Withdrawal: to extract resources from the system (use, consume: obtain connectivity from a network or interact through a device),

- Management: to regulate usage, make improvements, such as add features or improve interactions

- Exclusion: to determine who will have access and how this right can be transferred, and

- Alienation: the right to sell a portion of the resource (e.g. selling connectivity, services or content to others).

Participants can be different types of stakeholders: owners of their devices or connectivity, authorized to use them (withdrawal) under an end-user license but not citizens in political terms, being allowed (or not) to manage the digital infrastructure (define and decide on its rules, features, coverage, price, access rights) and its ownership (alienate, resell it).

Therefore due to ownership, control or economic reasons, many people may be excluded from these interactions. To break from these limits, citizens and organizations around the globe are creating selfprovided resources managed in commons (peer production) that enable new types of interactions with commons spaces and promote (re)designing technology and service norms to make it more locally appropriate and people-centered.

\section{real world projects exploring commons alternatives}


Through ongoing projects we are looking at two examples of critical infrastructures that can be organized as commons:

- eReuse.org, a circuit of devices: a pool of first and second-hand devices use and reused by citizens and organizations that work cooperatively to keep these devices operational, in circulation.

- guifi.net, a community network: a network infrastructure built by citizens and organizations who coordinate services and share resources to build a network and provide connectivity.

The fundamental principles of a commons, defined to be fully inclusive, revolve around 1) the openness of access (usage and contribution), and 2) the openness of participation (development, construction, operation, and governance) on the resource system and its community.

These fundamental principles, applied to a circular economy of digital devices and collaborative networks, result in resource systems that are collective goods, socially produced, and governed as common-pool resources.

The development of a new commons by citizens is a social production, also called peer production, because the participants work cooperatively to build the resource system. The CPR is the model chosen to hold and govern the resource system. The participants (individuals or organizations with their own rules) must accept the rules to join the resource system and must contribute the required resources to do it, but they keep the ownership of their contributions and the right to withdraw.

Below we briefly describe two commons initiatives, eReuse.org and guifi.net, as representatives of a global movement of local communities, organizations, and citizens that deal with collaborative production of digital devices and internet connectivity respectively. They cooperate to share digital devices and connectivity under a common governance and specific business models constituting an ecosystem around digital access.

\section{eReuse.org: moving towards a circular economy}

A circular economy is one that aims to keep products product in use, unlike recycling which happens at a product's end-of-life (see Figure 1). Reuse is when a product or source part is used again for its original purpose. It can be through repair, refurbishment and remanufacturing. If products are reused, they last longer, reducing expenditure in new consumer goods, creating jobs, and strengthening digital skills. Refurbishment refers to prepare a device for another user (data wipe, upgrade), and remanufacture is to create new devices from source parts and improve the aesthetics. In the world, there are more digital devices - such as desktops, laptops, tablets, and mobiles - than people. The overall potential of the reuse of digital devices can be compared to the number of devices renewed annually, in the range of billions, but a large fraction are dismantled well before the end of their usable life. This results in most electric and electronic equipment (EEE) being recycled too early, despite the demand for reuse coming from citizens (http://ec.europa.eu/public_opinion/index_en.htm) and particularly from marginalized communities. Considering participation in digital society as a human right [6], a circular economy can also help to reduce the digital divide and strengthen institutions and projects for social change. 


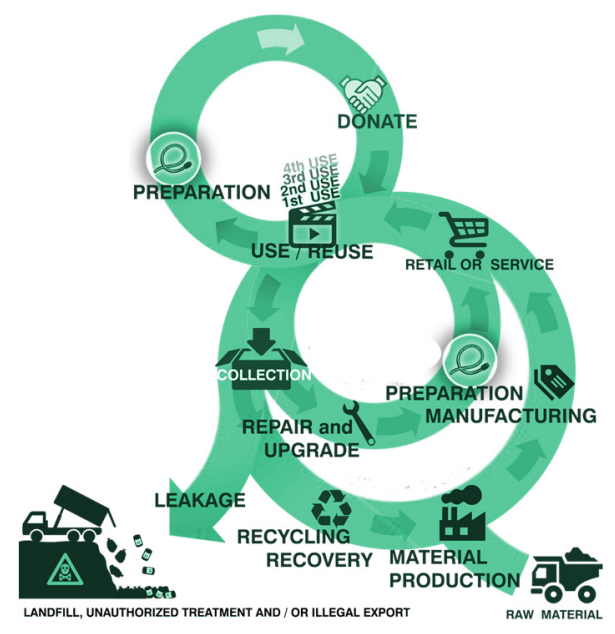

Figure 1: Reuse loops in the lifecycle of a digital device

The eReuse.org commons represents a global federation of local groups, organizations, and communities that deal with the circular life of digital devices in their target communities under specific business models. They cooperate to share information, methods, license, software services, and software tools under a common governance constituting an ecosystem around circular electronics.

In Spain there are several eReuse circuits, where public administrations, universities and companies create a pool of resources that are old but usable computers that are offered at more affordable prices. Social enterprises refurbish, repair, upgrade the devices, provide maintenance, collect and find receivers. In these reuse communities receivers only pay the cost to return a device to circulation, and not the cost of the product itself. All stakeholders interact using eReuse.org software tools and services for the traceability of devices and to optimize refurbishment, promote reuse and to finally ensure recycling at authorized points.

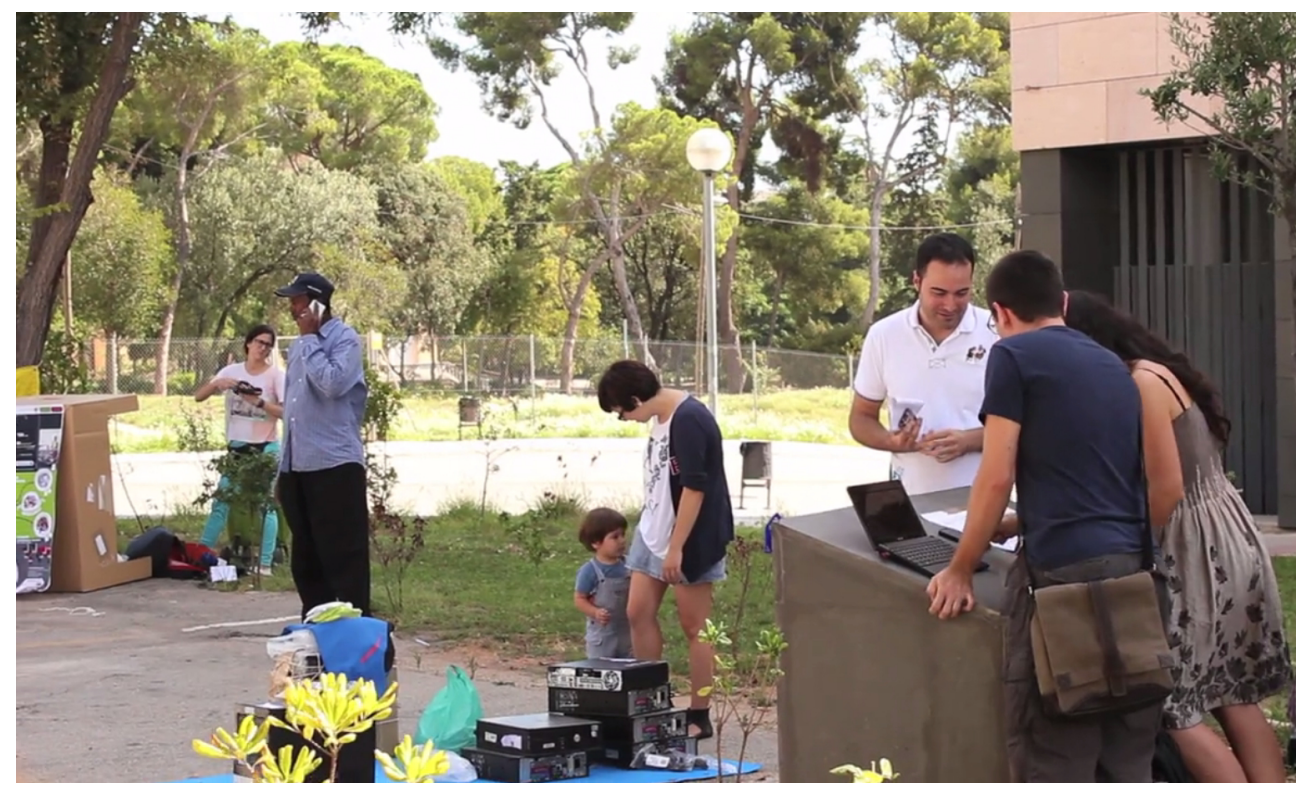

Figure 2: An outdoor activity where donors and recipients meet to deliver computers for reuse. 
eReuse circuits organize reuse events, such as the outdoors activity in Figure 2, where donors bring computers and citizens collect them. Companies, public administration and citizens donate devices to local circuits through a license of their choice, with terms and conditions (e.g. traceability: return after usage or recycle, not-for-profit receivers). Receivers get devices and must accept the terms of the license: i) keep devices in use and avoid premature recycling, through repair and upgrade of components, ii) facilitate device traceability (including components) using the software tools of the circuit to reduce loss and facilitate reuse, iii) returning to the circuit devices becoming future donors and iv) dispose of devices to authorized collection points for recycling only if there is no demand in a circuit. As a specific example, one eReuse circuit (Reutilitza.cat) has 12 social enterprises involved and has facilitated the donation of over 2,000 digital devices to over 1,000 social initiatives (January 2017).

\section{guifi.net: opening digital infrastructures}

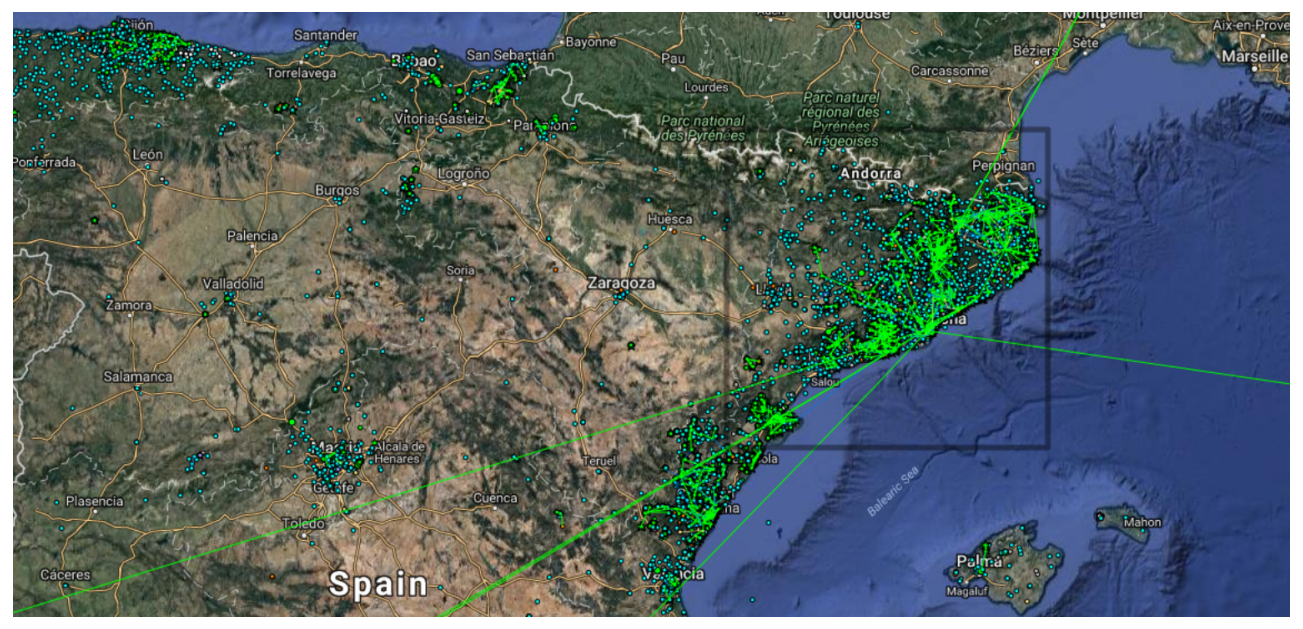

Figure 3: Partial map of the guifi.net community network infrastructure

Computer networks, provide an artificial medium for digital communication and access to information across distance and time that enhances our natural capacities to hear in the acoustic space, see in a narrow frequency band of visible light, and access information in the physical space around us.

In the past, telecom services and access to the Internet was often seen as optional, a luxury for corporations and those citizens able and willing to pay extra to benefit from these artificial "superpowers".

Yet more recently, communities of citizens have developed their own community networking infrastructures for local interconnection and access to the Internet. As one example, guifi.net is an open, free and neutral network infrastructure built and maintained by citizens and businesses who pool their resources and coordinate their efforts [1]. The guifi.net community network has more than 32,000 connections and a total length of $60,000 \mathrm{Km}$ (January 2017). Most of their nodes are located in Spain as seen in Figure 3, but there are many more similar initiatives around the world [2]. 


\section{A call for interaction}

Citizens and digitally excluded communities who become peer production actors can effectively acquire, build or repair their own digital devices and gain internet connectivity at a very low price. The two projects (eReuse.org and guifi.net) described above exemplify new forms of interactions between citizens, businesses and the common-pool resources that can provide digital inclusion to thousands of citizens in Spain and many other countries.

We argue that the future of societies around the world depends on accessible and participation, that citizens must be able to fully engage in the governance of the digital, not only as mere users or consumers. The current model of unequal access to digital devices and connectivity is clearly unfair and unsustainable. Too few participate in the design and governance of the digital world, kept to an elite of private interests. A minority of the world's population can enjoy the benefits of sleek devices and fast connectivity. Everyone is or will be influenced by the growing environmental impact of the digital world. If digitally excluded communities become peer production actors they will be able to build their own circular devices and sustainable network infrastructures, and they will have the opportunity to become active participants in the interactions of design and governance of the common digital space.

\section{Acknowledgments}

This work is supported by the European Community Framework Programme 7, Collective Awareness Platforms for Sustainability and Social Innovation (CAPS), project "Collective enHanced Environment for Social Tasks" (CHEST), contract 611333, the H2020 Programme netCommons H2020-688768, and the Spanish government TIN2016-77836-C2-2-R.

\section{References}

[1] Baig, R., Roca, R., Navarro, L. and Freitag, F. 2015. guifi.net: a network infrastructure commons. In Proceedings of the Seventh International Conference on Information and Communication Technologies and Development (ICTD '15). ACM, New York, NY, USA

[2] DC3. 2016. Community Connectivity: Building the Internet from Scratch. Annual Report of the UN IGF Dynamic Coalition on Community Connectivity (DC3). FGV

[3] Franquesa, D., Navarro, L., and Bustamante, X. 2016. A circular commons for digital devices: tools and services in ereuse.org. In Proceedings of the Second Workshop on Computing within Limits (LIMITS '16). ACM, New York, NY, USA.

[4] Global Information Society Watch (GISWatch). 2016 report on Economic, Social and Cultural rights (ESCRs). Association for Progressive Communications (APC), Humanist Institute for Development Cooperation (Hivos). http://giswatch.org.

[5] Ostrom, E. 1990. Governing the Commons: The Evolution of Institutions for Collective Action. Cambridge, UK: Cambridge University Press. ISBN 0521405998. 
[6] IFLA. 2005. Beacons of the Information Society: The Alexandria Proclamation on Information Literacy and Lifelong Learning. International Federation of Library Associations and Institutions (IFLA) and UNESCO.

http://www.ifla.org/publications/beacons-of-the-information-society-the-alexandria-proclamation-oninformation-literacy

[7] Schlager, E. and Ostrom, E. 2015. Property-Rights Regimes and Natural Resources: A Conceptual Analysis. Elinor Ostrom and the Bloomington School of Political Economy: Resource Governance, Vol 2. Lexington Books, USA. 